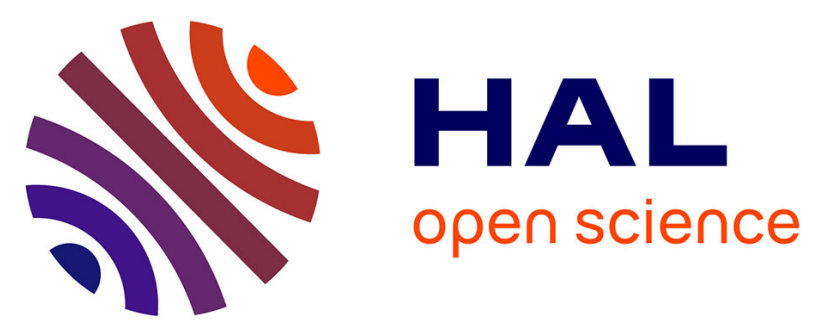

\title{
Short-term upper limb immobilization affects action-word understanding.
}

\author{
Christel Bidet-Ildei, Aurore Meugnot, Sophie-Anne Beauprez, Manuel
}

Gimenes, Lucette Toussaint

\section{To cite this version:}

Christel Bidet-Ildei, Aurore Meugnot, Sophie-Anne Beauprez, Manuel Gimenes, Lucette Toussaint. Short-term upper limb immobilization affects action-word understanding.. Journal of Experimental Psychology: Learning, Memory, and Cognition, 2017, 43 (7), pp.1129 - 1139. 10.1037/xlm0000373 . hal-01722554

\section{HAL Id: hal-01722554 https://hal.science/hal-01722554}

Submitted on 7 Jan 2019

HAL is a multi-disciplinary open access archive for the deposit and dissemination of scientific research documents, whether they are published or not. The documents may come from teaching and research institutions in France or abroad, or from public or private research centers.
L'archive ouverte pluridisciplinaire HAL, est destinée au dépôt et à la diffusion de documents scientifiques de niveau recherche, publiés ou non, émanant des établissements d'enseignement et de recherche français ou étrangers, des laboratoires publics ou privés. 
Short-term upper limb immobilization affects action-word understanding

Bidet-Ildei Christel, Meugnot Aurore, Beauprez Sophie-Anne, Gimenes Manuel \& Toussaint Lucette.

Université de Poitiers, Faculté des Sciences du Sport ; Université François-Rabelais de Tours;

Centre National de la Recherche Scientifique, Centre de Recherches sur la Cognition et l’Apprentissage, UMR 7295, Poitiers, France

Corresponding author: Christel Bidet-Ildei

Mailing Address:

Christel Bidet-Ildei $(\mathrm{PhD})$

CeRCA/MSHS, Bâtiment A5

5 , rue Théodore Lefebvre

TSA 21103

86073 Poitiers cedex 9

Tel.: 33 (0)5 49454697

Fax: 33 (0)5 49454616

Email: christel.bidet@univ-poitiers.fr 


\section{ABSTRACT}

The present study aimed to investigate whether well-established associations between action and language can be altered by short-term upper limb immobilization. The dominant arm of righthanded participants was immobilized for 24 hours with a rigid splint fixed on the hand and an immobilization vest restraining the shoulder, arm and forearm. The control group did not undergo such immobilization. In two experiments, participants had to judge whether a verb involved movements of the hands or feet. In Experiment 1, the response times for controls were shorter for hand-action verbs than for foot-action verbs, whereas there was no significant difference in the immobilized group. Experiment 2 confirmed these results with a pre/post test procedure. Shorter response times were shown for hand-action verbs than for foot-action verbs in the pre and post-tests for the control group and in the pre-test for the immobilized group (i.e., before immobilization). This difference was not observed for participants undergoing 24 hours of hand immobilization, who showed little progress in assessing hand-action verbs between pre-test and post-test. Moreover, participants with the highest motor imagery capacities clearly demonstrated shorter response times in Experiment 2 for both hand-action and foot-action verbs, regardless of hand immobilization. Overall, these findings demonstrate for the first time that short-term sensorimotor deprivation can affect action verb processing. We discuss our results in light of the embodiment view, which considers that cognition is grounded in sensorimotor experiences.

Key words: short-term immobilization, action word understanding, motor imagery 


\section{Introduction}

Consistent with the embodied view of cognition (Barsalou, 2008; Pulvermüller, 2013b), lots of studies have demonstrated a clear crosstalk between action-words processing and action (Fischer \& Zwaan, 2008; Jirak, Menz, Buccino, Borghi, \& Binkofski, 2010 for reviews). For example, behavioural experiments using a priming or a dual-task procedure have demonstrated that the presentation of an action word or an action sentence influences the characteristics of the following movement (Boulenger et al., 2006; Glenberg \& Kaschak, 2002; Liepelt, Dolk, \& Prinz, 2012) or the subsequent judgements of human movements (Bidet-Ildei, Gimenes, Toussaint, Almecija, \& Badets, 2016; Bidet-Ildei, Sparrow, \& Coello, 2011; Springer, Huttenlocher, \& Prinz, 2012; Springer \& Prinz, 2010). Otherwise, clinical reports have shown that the integrity of motor areas is essential for action word processing (Bak, O'Donovan, Xuereb, Boniface, \& Hodges, 2001; Boulenger et al., 2008; Cardona et al., 2013; Cotelli et al., 2006; Peran, Demonet, Pernet, \& Cardebat, 2004; Peran et al., 2003). A dominant hypothesis that explains the link between action and action word processing is based on the notion that both activities activate similar brain networks, including the mirror neuron system (Aziz-Zadeh \& Ivry, 2009; Aziz-Zadeh, Wilson, Rizzolatti, \& Iacoboni, 2006; Pulvermüller, 2005, 2013a; Pulvermuller \& Fadiga, 2010; Tettamanti et al., 2005). This motor activation would be somatotopic in primary motor cortex and pre-motor cortex (Hauk, Johnsrude, \& Pulvermuller, 2004) which is in accordance with the evocation of common sensorimotor representations (Andres, Finocchiaro, Buiatti, \& Piazza, 2015; Bidet-Ildei \& Toussaint, 2015; Willems \& Hagoort, 2007) and with the use of implicit motor imagery (Aziz-Zadeh \& Ivry, 2009; Willems, Toni, Hagoort, \& Casasanto, 2010) during action words processing. Interestingly, the relationship between action and action-words appears early in childhood as evidenced by the recruitment of motor areas in 4-5 years-old children when they have to process action verbs (James \& Maouene, 2009). Moreover, some studies have shown that new associations between words and action can appear rapidly with training (e.g., Fargier et al., 2012; Kiefer, Sim, Liebich, Hauk, \& Tanaka, 2007). For example, Fargier et al. (2012) have shown that one day of training is sufficient 
to associate correctly observed actions to novel verbal stimuli and to detect motor activation when these new verbal stimuli are processed.

Altogether, these experiments argue in favour of embodied cognition and demonstrated that "concepts are grounded in perception and action" (Fargier et al., 2012). However, an open issue is to determine whether well-established associations can be altered by a quick update of sensorimotor representations. Recently, short-term upper limb immobilization in healthy subjects was proposed as a new paradigm to explore how experience affects brain functions. In this context, some studies have shown that a brief period of upper limb immobilization (12 to 48 hours) is sufficient to induce cortical plastic changes and functional or behavioural consequences (Bassolino, Bove, Jacono, Fadiga, \& Pozzo, 2012; Facchini, Romani, Tinazzi, \& Aglioti, 2002; Huber et al., 2006; Meugnot, Almecija, \& Toussaint, 2014; Moisello et al., 2008; Toussaint \& Meugnot, 2013). For example, it has been demonstrated that short-term arm immobilization directly affects motor performance by decreasing endpoint accuracy and modifying the kinematics associated with arm movement (Bassolino et al., 2012; Moisello et al., 2008). Similarly, 48 hours, and even 24 hours, of hand immobilization affected the cognitive representations of upper limb movements, as confirmed by delayed response times in a hand mental rotation task, which is known to trigger sensorimotor memories of hand movements (Meugnot et al., 2014; Toussaint \& Meugnot, 2013). These behavioural changes are associated with a decrease in cortical excitability (Facchini et al., 2002) and a decrease in both somatosensory and motor-evoked potentials elicited from sites over the contralateral sensorimotor cortex (Huber et al., 2006). This selective impairment of limb immobilization, which was observed in the contralateral hemisphere but not the ipsilateral hemisphere, has been confirmed in behavioural studies. For example, less accurate pointing movements have been observed for only the immobilized arm (Huber et al., 2006). Moreover, Meugnot et al. (2014) reported that a decrease in input-output signal processing due to left hand immobilization specifically affected the cognitive representation of left hand movements without affecting right hand movements. Finally, upper limb immobilization specifically affected the upper limb representations without affecting the cognitive 
representations of lower limb movements (Meugnot, Agbangla, \& Toussaint, 2016). Although these types of experiments are rarely reported in the literature, they clearly demonstrate that sensory motor deprivation over a brief period directly affects movement production and cognitive motor processing (i.e., motor imagery) associated with a slowdown of sensorimotor processes. Specifically, short-term limb immobilization may provide an ideal method for temporally disturbing the sensorimotor system to assess its contribution to the processing of mental phenomenon other than action (e.g., motor simulation, Toussaint \& Meugnot, 2013).

In the present study, we investigated whether perturbation of sensorimotor representations related to short-term limb immobilization can affect action verbs processing in healthy participants. For this purpose, we used a semantic decision task implying action verbs.

\section{Experiment 1}

In Experiment 1, we aimed to demonstrate that upper limb immobilization affects the performance of a semantic decision task consisting of action verbs that mainly involve movements of the hands or feet. We compared performances on a single session performed after 24 hours of right hand immobilization or by participants who did not undergo the immobilization procedure. For each verb that appeared on the computer screen, participants were asked to answer "hand" or "foot", when they considered that action was mainly performed by upper or lower-limbs, respectively. We made the assumption that the effector-induced effects of short-term upper limb immobilization (Meugnot, Agbangla, \& Toussaint, 2015; Meugnot, Almecija, \& Toussaint, 2014) should manifest specifically for judgements of hand-action verbs (e.g., write) without disrupting judgements of foot-action verbs (e.g., jump). More specifically, we hypothesized that judgement of hand action verbs should be slowed in the immobilized group related with a specific slowdown of sensorimotor processes.

\subsection{Method}

\subsubsection{Participants}

Thirty-six right-handed French-speaking university students (18-26 years old, mean age = 
20.3 years; 20 males, 16 females) participated in the experiment. They were separated randomly into 2 groups of 18 participants: a control group (mean age $=19.6 ; 11$ males, 7 females) and an immobilized group (mean age $=21.0 ; 9$ males, 9 females). Each participant was healthy, had normal or corrected-to-normal vision and had no history of motor or neurological disorders. The participants were naïve of the experiment's aims before testing.

\subsubsection{Task and procedure}

All participants performed a semantic decision task that involved action verbs. They were seated in front of the computer screen and had to decide whether an action verb described movements performed mainly with the hands (e.g., write, cut, clap) or with the feet (e.g., pedal, run, jump). Forty-four action verbs (22 hand-action verbs and 22 foot-action verbs) were selected from the French lexical database Lexique 2.0 (New, Pallier, Ferrand \& Matos, 2001). All action verbs were in the infinitive form (see Appendix $\mathrm{A}_{.3}$ and $\mathrm{A}_{.4}$ for more details). Hand-action verbs and footaction verbs were matched for relevant lexical variables including word frequency, number of letters and number of syllables (Table 1).

Table1. Mean values of action verb frequency (FQ), number of letters (LETT) and number of syllables (SYLL) for hand- and foot-action verbs. ANOVAs are reported in the last column.

\begin{tabular}{cccc}
\hline & $\begin{array}{c}\text { Hand-action } \\
\text { verbs }\end{array}$ & $\begin{array}{c}\text { Foot-action } \\
\text { verbs }\end{array}$ & ANOVA (by item) \\
\hline FQ & 42.9 & 43.4 & $\mathrm{~F}(1,42)=0.01, p=.98$ \\
\hline LETT & 6.95 & 7.32 & $\mathrm{~F}(1,42)=1.02, p=.38$ \\
\hline SYLL & 2.41 & 2.59 & $\mathrm{~F}(1,42)=1.20, p=.28$ \\
\hline
\end{tabular}


The semantic decision task was divided into two phases. During the first training phase, participants were shown 3 hand-action verbs and 3 foot-action verbs in a random order. No time constraint was imposed during the training phase. During the second experimental phase, the participants were shown 132 randomly presented action verbs ( 3 trials each of 22 hand-action verbs and 22 foot-action verbs which were different than those used in the training phase). Each trial began when a fixation cross was displayed in the centre of the screen for $500 \mathrm{~ms}$. Then, an action verb was presented and remained visible until the participant gave a verbal response ("main" or "pied", French words meaning "hand" and "foot", respectively). A blank screen appeared during the 500-ms period that preceded the next trial. The participants had to respond as fast and as accurately as possible. The E-prime 2.0 software package (Psychology Software Tools Inc., Pittsburgh, USA) was used to present the action verbs and to record the participant's response times via a microphone connected to the computer. For each trial, the experimenter wrote and assessed the correctness of the participant's answers on a sheet.

The semantic decision task was performed in a single session for each participant. For the immobilized group, a rigid splint (model DONJOY "Comfort Digit", DJO, Surrey, UK) fixed on the hand and an immobilization vest restraining the shoulder, arm and forearm (model DONJOY "Immo Axmed") were used to ensure the participants kept their right upper limb at rest as much as possible during 24 hours. The participants were instructed to not remove the splint during the immobilization period; however, they could remove the immobilization vest for the night. To quantitatively verify whether participants followed the instructions, we monitored the physical activity of both hands through actimeters (pounds/min) placed on each hand. During the 24-hour delay, an average of $422 \pm 199$ pounds/min $(3.2 \pm 1.5 \mathrm{~kg} / \mathrm{s})$ were recorded for the right immobilized hand and $2018 \pm 620$ pounds $/ \mathrm{min}(15.3 \pm 4.7 \mathrm{~kg} / \mathrm{s})$ were recorded for the left non-immobilized hand (see Toussaint \& Meugnot, 2013, for a similar procedure). An ANOVA performed on the actimeter values showed that the level of activity was significantly higher for the left hand than for the right 
hand, $F(1,17)=139.3, p=0001, \eta^{2}=.89$. The immobilization group performed the semantic decision task immediately after the splint and the immobilization vest were removed. The other group served as the control (i.e., without immobilization). At the end of the task, participants who have been immobilized were asked to perform some movements of flexion/extension to reactivate their sensorimotor system (Bassolino et al. 2012).

\subsubsection{Data analysis}

Accuracy and response times were recorded for each trial. Unreliable trials due to hesitations or microphones failures have been excluded of the analysis (less than $2 \%$ of all trials). Only data from correct responses were used to analyze response times. For all conditions, means and standard deviations were reported in Appendix $\mathrm{A}_{.1}$. Accuracy and response times analyzes were performed with generalized linear mixed-effects models using the lme4 package (Bates, Maechler, Bolker \& Walker, 2015) in the R environment ( $\mathrm{R}$ version 3.3.0, R Core Team, 2014). In all models, participants and items were specified as random-effects factors. Two fixed-effects factors were included (group, action verbs and their interaction). The p-values were obtained using the lmerTest package (Kuznetsova, Bruun Brockhoff \& Haubo Bojesen Christensen, 2014).

\subsection{Results}

The accuracy analyzes showed no significant main effects for neither group nor action verbs as well as no significant interaction between groups and action verbs. On average, the response accuracy was $98 \% \pm 2.3 \%$ (mean \pm standard deviation).

The analyzes performed for response times showed no significant main effects. However, the interaction between groups and action verbs was significant $: F(1,4362.8)=6.7, p=.01$. Contrast analyzes revealed that response times were faster for the hand-action verbs than for the foot-action verbs for the control group $(p=.05)$, whereas no difference was observed for the immobilized group $(p=.73)$ (Figure 1). 


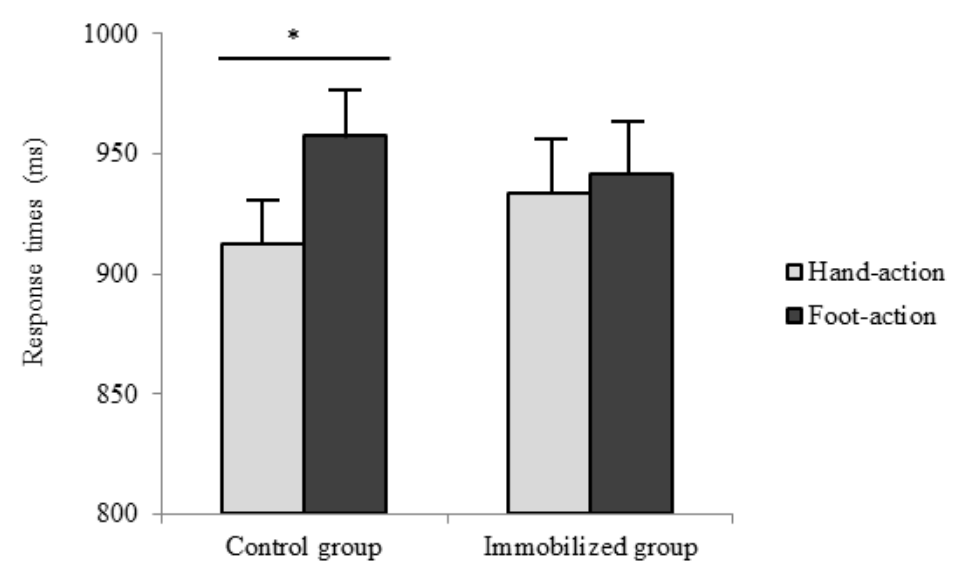

Figure 1. Response times (ms) according to group (control / immobilized) and action verb (handaction / foot-action). The error bars indicate the standard error of the mean. Asterisks* indicates a significant difference with $p=0.05$.

Given that effects appeared only in response times, it excluded an explanation in terms of speedaccuracy trade-off.

\subsection{Discussion}

The objective of this experiment was to assess whether short-term upper limb immobilization can affect action verb processing. We made the assumption that differences would be observed between groups for judgements regarding hand action verbs. The results showed an interesting within-group difference: subjects who did not undergo immobilization were faster at judging hand-action verbs than foot-action verbs, whereas this difference was not present when the participants had been immobilized during the previous 24 hours. Before considering the effect of immobilization on action verb judgement, we propose to examine the difference observed between hand-action and foot-action verbs in control group in the following section.

At first level, the advantage obtained in response times for hand-action verbs could be simply due to the response modality. Participants had to respond "hand" ("main" in French) or 
"foot" ("pied" in French) in a microphone. Several works have shown that times in word naming task vary substantially as a function of onset phoneme (e.g., Spieler \& Balota, 1997) and some works have shown a nonplosive phoneme advantage (e.g., Ferrand et al., 2011). However, time differences are very small (about $4.5 \mathrm{~ms}$ ) and they could not explain in totality time differences obtained in our experiment (about $40 \mathrm{~ms}$ ). Moreover, this explanation can hardly account for the advantage for hand-action verbs before immobilization that disappears after immobilization.

It is possible to consider that difference in response times could also be related to a higher language familiarity for hand-action verbs (e.g., Ando, Kida, \& Oda, 2002; Taniguchi, 1999) . Nevertheless, given that hand-action and foot-action verbs were controlled in terms of linguistic parameters (i.e., frequency) in our experiment, we can assume that verbal experience was similar between both categories of verbs and therefore a faster response time cannot be attributed to language practice.

One other possibility is that the hand-action verbs advantage could be related to attentional mechanisms for a body-specific system (see Connell \& Lynott, 2012 for a review). For example, Connell, Lynott and Dreyer (2012) reported a facilitation effect when people had to compare manipulable objects (versus non manipulable objects) with concurrent tactile stimulation of the hands, due to the fact that perceptual stimulation directed attention toward the hand. However, in our study, although participants were informed that experimental manipulations were applied to the hand, the hand-action verb advantage disappeared following 24 hours of hand and arm immobilization whereas attentional mechanisms towards the hand are probably strengthened by the difficulties link to the hand non-use. In our opinion, these results discount the hypothesis that handaction verbs advantage is due to the increase attentional demands on the hand.

According to the embodied view of cognition, an alternative explanation might be that handaction and foot-action verbs are associated with different levels of sensorimotor representations. At the neurophysiological level, this difference might be directly related to the motor homunculus of the primary motor cortex (Penfield \& Boldrey, 1937). Indeed, it is acknowledged that cortical 
representations of body parts are not proportional to the size of the body part but rather to the complexity of movements such body parts can produce. Specifically, the hand is more represented in the sensorimotor cortex than the foot. As a previous study revealed that action word processing somatotopically activates the primary motor cortex (e.g., Hauk, Johnsrude, \& Pulvermuller, 2004), we hypothesized that faster response times obtained for hand-action verbs might be related to the largest hand representation in the primary motor cortex. As underlined by an anonymous reviewer, if this explanation is correct, cortical somatosensory maps might be used to predict individual response times. For instance, whole-body action verbs should be identified faster than mere handor foot-action verbs. However, this explanation remains speculative and future experiments have to assess this point by combining behavioural and cerebral activation data (see Heim, Mayberg, Mletzko, Nemeroff, \& Pruessner, 2013 for an experiment on this question).

Finally, it is possible to envisage that difference between hand and foot related verbs might be related to sensorimotor experience. This notion accords with the fact that personal motor experience influences the degree of motor activation during language understanding. Accordingly, greater activation was observed in the left premotor cortex in experienced ice hockey players who analyzed sentences that presented specific hockey actions than in non-experienced ice hockey players analysing the same sentences (Lyons et al., 2010). In the present experiment, assuming that hand movements are common in humans, we can hypothesize that sensorimotor representations associated with hand-action verbs could generate greater activity in the central nervous system than sensorimotor representations associated with foot-action verbs. This hypothesis remains to be assessed in future experiments; however, this notion is consistent with a previous study that showed motor practice directly influences motor system activation during action word processing (Fargier et al., 2012).

Interestingly, in the current experiment, the effects induced by 24 hours of upper limb immobilization were manifest by the absence of a difference between processing for handaction verbs and foot-action verbs compared with controls, suggesting that short-term sensorimotor 
deprivation directly affects action verb processing. Although experimental evidence still needed (as done in experiment 2), it may be that hand immobilization during 24 hours slowdown the judgement of hand action verbs suggesting that well-established associations between action and action-verbs processing can be affected by peripheral sensorimotor deprivation. This notion is consistent with previous investigations that demonstrated that short-term immobilization affects sensorimotor representations (Toussaint \& Meugnot, 2013, see general discussion for more details) relating with a decrease of cerebral activity in sensory and motor cortices controlling the immobilised limb (Huber et al., 2006). However, as this experiment was performed with two different groups, we cannot exclude that our results might be related to individual differences in sensorimotor experience rather than the immobilization procedure. Experiment 2 aimed to exclude this alternative hypothesis by assessing the effects of immobilization with a pre/post-test procedure.

\section{Experiment 2}

The first objective of the present experiment aimed to confirm the impact of short-term upper limb immobilization on action verb processing. Here, a pre/post-test procedure was used to ensure that the effects obtained in Experiment 1 were directly related to sensorimotor deprivation and not to individual differences as previously mentioned. In that case, we could expect that a difference in response times between the hand-action and foot-action verbs observed in Experiment 1 would be present in both the control and the immobilized groups in the pre-test, but it would not be present in the post-test for only the immobilized group. Moreover, our experimental design included a test of the individual's motor imagery capability using the Vividness of Motor Imagery Questionnaire (VMIQ, Isaac, Marks, \& Russell, 1986). Previous experiments have shown that motor simulation is involved during action word processing (Aziz-Zadeh \& Damasio, 2008) and that the immobilization-induced effects had a greater effect on the sensorimotor representations of participants with a greater motor imagery capacity (from a first-person perspective) compared to participants who had lesser motor imagery capacities (Toussaint \& Meugnot, 2013; Willems \& 
Hagoort, 2007). Therefore, a second objective of this experiment was to assess the role of individual imagery capacities in the relationship between sensorimotor processes and action verb judgement.

\subsection{Method}

\subsubsection{Participants}

Thirty-two right-handed French-speaking university students (18-29 years, mean age = 19.75 years; 10 males, 22 females) participated in the experiment. They were assigned randomly to 2 groups of 16 participants: a control group (mean age $=18.9 ; 6$ males, 10 females) and an immobilized group (mean age $=20.6 ; 4$ males, 12 females). Each participant was healthy, had normal or corrected-to-normal vision and had no history of motor or neurological disorders. The participants were naïve to the aims of the experiment before testing.

\subsubsection{Tasks and procedure}

The task and procedure were similar to those used in Experiment 1, except that in Experiment 2, the semantic decision task was performed during 2 experimental sessions with a 24$\mathrm{hr}$ interval between sessions (pre-test and post-test). The task was performed before immobilization (pre-test) and immediately after the splint and immobilization vest were removed (post-test) for the immobilized group. The actimeters revealed that, on average, $496 \pm 223$ pounds $/ \mathrm{min}(3.7 \pm 1.7 \mathrm{~kg} / \mathrm{s})$ and $2300 \pm 532$ pounds/min $(17.4 \pm 4.02 \mathrm{~kg} / \mathrm{s})$ were recorded for the right immobilized hand and left non-immobilized hand, respectively. The ANOVA performed for the actimeter data showed that the level of activity was significantly higher for the left hand than for the right hand, $F(1,15)=109.4$, $p=000, \eta_{p}^{2}=.88$.

At the beginning of the experiment, all participants completed the Vividness Movement Imagery Questionnaire (VMIQ; Isaac, Marks \& Russell, 1986). The VMIQ consists of 24 items relevant to both first-person (i.e., internal imagery) and third-person perspective imagery (i.e., external imagery). The measures of imagery vividness were assessed for each imagery perspective on a 5-point Likert-type scale. High scores represent low vividness of movement imagery (for the first-person and the third-person perspectives), with the reverse being true for low scores. The mean 
VMIQ scores are illustrated in Table 2.

Table2. The means, standard deviations, and ranges for Scores Measuring the Vividness of Movement Imagery from a first-person perspective (i.e., internal imagery) and a third-person perspective (i.e., external imagery) for both the control and immobilized groups.

\begin{tabular}{llcc}
\hline Group & & $\begin{array}{c}\mathbf{1}^{\text {st }} \text {-person } \\
\text { perspective }\end{array}$ & $\begin{array}{c}\mathbf{3}^{\text {rd }} \text {-person } \\
\text { perspective }\end{array}$ \\
\hline Control & M & 48.3 & 43.7 \\
& SD & 14.0 & 14.7 \\
& Range & $25-76$ & $24-71$ \\
\hline Immobilized & M & & 42.6 \\
& SD & 51.6 & 14.5 \\
& Range & 16.3 & $24-75$ \\
\hline
\end{tabular}

ANOVAS performed on each imagery perspective separately did not reveal any significant difference between the control and the immobilized group $\left(F(1,30)=0.39, p=.53\right.$ for the $1^{\text {st }}$-person perspective; $F(1,30)=0.04, p=.83$ for the $3^{\text {rd }}$-person perspective).

\subsubsection{Data analysis}

Accuracy and response times were recorded for each trial. Unreliable trials due to hesitations or microphones failures have been excluded of the analysis (less than $1.5 \%$ of all trials). Only data from correct responses were used to analyze the response times. For all conditions, means and standard deviations were reported in Appendix $\mathrm{A}_{2 .}$.

To quantify the improvement in response times between the pre-test and post-test for the judgement of hand and foot-action verbs in both the control and the immobilized groups, we computed the Index of Performance Improvement (IPI = [response time in pre-test - response time in post-test] / response time in pre-test, expressed in percentage) for each participant and each action verb. A positive value indicated that response times decreased from the pre-test to post-test (i.e., 
performance improvement), whereas a negative value indicated that response times increased (i.e., performance deterioration). The same procedure was followed for IPI accuracy. IPI Accuracy and IPI response times analyzes were performed with generalized linear mixed-effects models using the lme4 package (Bates, Maechler, Bolker \& Walker, 2015) in the $\mathrm{R}$ environment ( $\mathrm{R}$ version 3.3.0, $\mathrm{R}$ Core Team, 2014). In all models, participants and items were specified as random-effects factors. Two fixed-effects factors were included (group, action verbs and their interaction). The p-values were obtained using the lmerTest package (Kuznetsova, Bruun Brockhoff \& Haubo Bojesen Christensen, 2014).

\subsection{Results}

Analyzes performed for IPI accuracy failed to show significant main effects for group and for action verbs and showed no significant interaction between groups and action verbs ( $p s>.38)$.

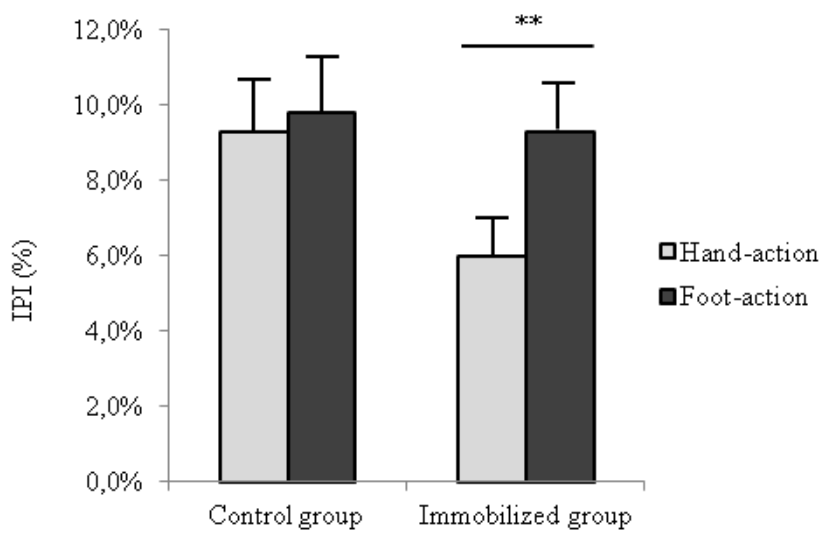

Figure 2. Index of Performance Improvement (\%) according to group (control / immobilized) and action verbs (hand-action / foot-action). The error bars indicate the standard error of the mean. Asterisks** indicate a significant difference with $p<0.01$.

Analyzes performed on IPI response times revealed no significant main effects. However, the interaction between group and action verbs was significant: $\mathrm{F}(1,1323.36)=3.71, \mathrm{p}=.05$. Contrast analyzes revealed that the IPI was lower for the hand-action verbs than for the foot-action verbs in 
the immobilized group ( $p=.008)$, whereas no significant difference was observed in the control group ( $p=.74)$ (Figure 2).

Finally, we examined whether performance in the semantic decision task (for the handaction and foot-action verbs) depended on imagery capacity as evaluated by the VMIQ (Isaac et al., 1986). We examined pairwise Pearson's correlations between the response times recorded in the semantic decision task and the first-person perspective imagery scores, as well as between the response times and the third-person perspective imagery scores for the control group and the immobilized group in the pre-test and post-test procedures (see Table 3).

Table3. Correlation coefficients (and $p$-values) between response times recorded for the hand-action and foot-action verbs and the imagery scores (VMIQ) for the control and immobilized groups in the pre-tests and post-tests. An asterisk * indicates a significant correlation.

\begin{tabular}{ccccc} 
Group & Session & Action verbs & $\begin{array}{c}\mathbf{1}^{\text {st }} \text {-person } \\
\text { perspective }\end{array}$ & $\begin{array}{c}\mathbf{3}^{\text {rd }} \text {-person } \\
\text { perspective }\end{array}$ \\
\hline Control & Pre-test & Hand-action & $r=.53(p=.034)^{*}$ & $r=.08(n s)$ \\
& Post-test & Hand-action & $r=.49(p=.054)^{*}$ & $r=.01(n s)$ \\
& Pre-test & Foot-action & $r=.52(p=.038)^{*}$ & $r=.16(n s)$ \\
& Post-test & Foot-action & $r=.51(p=.043)^{*}$ & $r=.01(n s)$ \\
\hline Immobilized & Pre-test & Hand-action & $r=.59(p=.016)^{*}$ & $r=.09(n s)$ \\
& Post-test & Hand-action & $r=.58(p=.018)^{*}$ & $r=.07(n s)$ \\
& Pre-test & Foot-action & $r=.58(p=.018)^{*}$ & $r=.21(n s)$ \\
& Post-test & Foot-action & $r=.58(p=.018)^{*}$ & $r=-.21(n s)$ \\
& & & & \\
\hline
\end{tabular}

As illustrated in Table 3, significant correlations were found for only first-person perspective scores, which were observed for both groups in the pre-test and post-test procedures. The positive correlation coefficients indicated that participants who were faster in performing the semantic decision tasks were the participants who reported lower first-person perspective imagery scores (i.e., those with a high capability for imaging from an internal perspective) whenever the semantic 
decision task was performed (i.e., before or after right hand immobilization).

\subsection{Discussion}

Experiment 2 aimed to replicate and extend the results obtained in Experiment 1. By using a pre/post-test procedure, we assessed whether short-term upper limb immobilization affected action verb processing.

IPI analyzes showed that the improvement in action verb judgement observed in the posttest was lesser for the hand-action verbs in the immobilized group, whereas improvement was similar for both hand-action and foot-action verbs in the control group. Moreover, we showed that action verb processing efficiency was dependent on the individual level of motor imagery (as assessed by the first-person perspective scores of the VMIQ), whereas no correlation was observed with visual imagery capacity (assessed by the third-person perspective scores of the VMIQ).

Overall, these findings confirm the results obtained in Experiment 1 by showing that sensorimotor deprivation disturbed action verb processing. Moreover, the present findings clearly demonstrate that the short-term hand immobilization affected specifically the judgement of handaction verbs, confirming the specific effector-induced effects of short-term upper limb immobilization (Meugnot, Agbangla, \& Toussaint, 2015; Meugnot et al., 2014). The slowdown in sensorimotor processes induced by short-term upper limb immobilization (Meugnot et al., 2014, 2015) could explain that response times were delayed specifically for the judgement of hand-action verbs (versus foot-action verbs).

Importantly, our findings demonstrate that motor imagery processes are specifically implied during a semantic decision task with action verbs before and after immobilization. This suggests that disrupting the processing of input/output signals during a short delay does not preclude the involvement of sensorimotor processes in action verb processing. As suggested by previous works, our results argue in favour of the use of a motor action simulation during action verb understanding (Aziz-Zadeh \& Damasio, 2008; Gallese, 2005; Kemmerer \& Gonzalez-Castillo, 2008; Pulvermüller, 
2005; Willems \& Hagoort, 2007). Therefore, when the motor action simulation processes are slowdown by peripheral changes such as sensorimotor deprivation, action verb understanding are slowdown in turn in a somatotopic way (i.e., according to the immobilized body-part).

\section{General Discussion}

The current experiments were designed to explore the effects of a brief delay of sensorimotor deprivation on action verb processing. Without immobilization, we observed systematically faster response times associated with the judgements of hand-action verbs than with foot-action verbs. This difference disappeared after 24 hours of immobilization, as evidenced by less improvement in hand-action verb judgement (Experiment 2). Interestingly, Experiment 2 also showed that the understanding of action verbs was directly related to an individual's vividness of motor imagery $\left(1^{\text {st }}\right.$-person perspective only) before and after immobilization.

Overall, these findings clearly corroborate previous studies that show that sensorimotor representations are directly involved in action verb processing and is associated with activation of a mirror neuron system (Andres et al., 2015; Aziz-Zadeh \& Ivry, 2009; Aziz-Zadeh et al., 2006; Bidet-Ildei et al., 2011; Bidet-Ildei \& Toussaint, 2015; Tettamanti et al., 2005). Moreover, the present findings demonstrate for the first time that 24 hours of limb immobilization is sufficient to modify action verb processing, confirming the embodied view of cognition, which indicates that higher cognitive functions are directly related to sensorimotor experience (Barsalou, 1999, 2008).

As proposed in previous studies, the effects of immobilization might be related to plastic changes in the sensorimotor areas (Huber et al., 2006; Moisello et al., 2008) or to difficulties in accessing or activating sensorimotor representations due to reduced processing of proprioceptive feedback from the immobilized hand (Meugnot \& Toussaint, 2015; Toussaint \& Meugnot, 2013). However, as the task used in the present experiment implies at least implicitly the evocation of motor imagery, it stays difficult here to distinguish whether short-term immobilization affects action verbs processing in general or only tasks implying motor imagery. As several works evoke that motor imagery occurs 
automatically as a component of everyday language processing (Pulvermüller, 2005; Zwaan \& Taylor, 2006), it may be that short-term immobilization can affect all tasks implying action verbs processing but this would be assessed in future experiments.

Importantly, our findings show that short-term upper limb immobilization specifically affected the processing of hand-action verbs with less progress between pre-tests and post-tests. This confirms that 24 hours of sensorimotor deprivation has an effect on specific body parts representation (Meugnot et al., 2016). As participants had their arms splinted, it is possible that the effect observed could be simply related to a grabbing attention for hand movements which could cause an interference (Connell \& Lynott, 2012). Even this hypothesis can be properly assessed only by the use of a more implicit task (e.g., lexical decision task) or by the adding of an attention load condition (e.g., memorise hand-action verbs), this attention explanation is less probable because the experimental manipulation was known by both groups of participants and a pure attentional explanation fails to account for the facilitation obtained in the control group. More probably, the slowdown observed for the judgement of hand-action verbs after immobilization could be related with the slowdown of sensorimotor processes attributed to the decrease in input-output signal processing for the immobilized right hand (Meugnot, Agbangla, Almecija, \& Toussaint, 2015; Meugnot et al., 2014; Meugnot \& Toussaint, 2015; Toussaint \& Meugnot, 2013) could be behind the limited improvement in judging hand-action verbs from pre-tests to post-tests observed in the immobilized group.

Notably, action verb understanding was directly related to an individual's vividness of motor imagery before and after the immobilization. This finding confirms that imagery capabilities are directly implicated in action verb processing (see Aziz-Zadeh \& Damasio, 2008; Kemmerer \& Gonzalez-Castillo, 2008; Pulvermüller, 2005; Willems \& Hagoort, 2007 for reviews). Interestingly, these correlations exists only with the first-person perspective suggesting that action verb processing is specifically related with motor (not visual) imagery competencies (Hostetter \& Alibali, 2008). Moreover, this pattern persists after 24 hours of immobilization suggesting that motor 
imagery is systematically involved in semantic decision tasks that require action verb processing (Pulvermuller, 2005 ; see Willems, Toni, Hagoort, \& Casasanto, 2010 for contreversials evidences). However, as previous works have shown that sensorimotor disorders can affect the use of firstperson perspective in case of co-speech action gestures (Humphries, Holler, Crawford, Herrera, \& Poliakoff, 2016), future researches will need to determine whether correlations between action verb processing and motor imagery capabilities persist with a longer period of immobilization that could induce stronger sensorimotor deficits.

In conclusion, the present work shows for the first time that short-term limb immobilization can affect action verb processing, the quick update of sensorimotor representation having direct consequences on the well-established associations between language and action. Moreover, our study confirms by using an original methodology (i.e., short-term upper limb immobilization in healthy participants) that processing action verbs activates somatotopic representations in the sensorimotor cortex (Hauk et al., 2004). This means that a specific re-education of language could be envisaged after sensorimotor deprivation. Importantly, a novel contribution of our approach is that our work assesses a novel paradigm (i.e., short-term immobilization) to study crosstalk between the motor system and action verb processing.

\section{FUNDING}

This work was supported by a grant from the National Centre for Scientific Research (CNRS, France).

\section{ETHICAL CONSIDERATION}

All aspects of this study were performed in accordance with the ethical standards set out in the 1964 Declaration of Helsinki and its later amendments. The study was approved by the local ethics committee of the institution - Centre for Research in Cognition and Learning (CeRCA) — and was 
conducted in accordance with national norms and guidelines for the protection of human subjects (CPP, $\mathrm{N}^{\circ}$ 2014-A00053-44). All participants gave their informed consent prior to their inclusion in the study and received $€ 20$ for their participation. All authors declare that they have no conflict of interest.

\section{REFERENCES}

Ando, S., Kida, N., \& Oda, S. (2002). Practice effects on reaction time for peripheral and central visual fields. Perceptual and Motor Skills, 95(3 Pt 1), 747-751. https://doi.org/10.2466/pms.2002.95.3.747

Andres, M., Finocchiaro, C., Buiatti, M., \& Piazza, M. (2015). Contribution of motor representations to action verb processing. Cognition, 134, 174-84. https://doi.org/10.1016/j.cognition.2014.10.004

Aziz-Zadeh, L., \& Damasio, A. (2008). Embodied semantics for actions: findings from functional brain imaging. Journal of Physiology Paris, 102(1-3), 35-9.

Aziz-Zadeh, L., \& Ivry, R. B. (2009). The human mirror neuron system and embodied representations. Advances in Experimental Medecine and Biology, 629, 355-76.

Aziz-Zadeh, L., Wilson, S. M., Rizzolatti, G., \& Iacoboni, M. (2006). Congruent embodied representations for visually presented actions and linguistic phrases describing actions. Current Biology, 16(18), 1818-23.

Barsalou, L. W. (1999). Perceptual symbol systems. Behavioral Brain Sciences, 22(4), 577-609-60.

Barsalou, L. W. (2008). Grounded cognition. Annual Review of Psychology, 59, 617-45. https://doi.org/10.1146/annurev.psych.59.103006.093639

Bassolino, M., Bove, M., Jacono, M., Fadiga, L., \& Pozzo, T. (2012). Functional effect of shortterm immobilization: kinematic changes and recovery on reaching-to-grasp. Neuroscience, 215, 127-34. https://doi.org/10.1016/j.neuroscience.2012.04.019

Bates, D., Maechler, M., Bolker, B., \& Walker, S. (2015). Fitting Linear Mixed-Effects Models Using lme4. Journal of Statistical Software, 67(1), 1-48.

Bidet-Ildei, C., Gimenes, M., Toussaint, L., Almecija, Y., \& Badets, A. (2016). Sentence plausibility influences the link between action words and the perception of biological human movements. Psychological Research. https://doi.org/10.1007/s00426-016-0776-z

Bidet-Ildei, C., Sparrow, L., \& Coello, Y. (2011). Reading action word affects the visual perception of biological motion. Acta Psychologica (Amst), 137(3), 330-4. https://doi.org/10.1016/j.actpsy.2011.04.001

Bidet-Ildei, C., \& Toussaint, L. (2015). Are judgments for action verbs and point-light human actions equivalent? Cognitive Processing, 16(1), 57-67. https://doi.org/10.1007/s10339-0140634-0

Boulenger, V., Roy, A. C., Paulignan, Y., Deprez, V., Jeannerod, M., \& Nazir, T. A. (2006). Crosstalk between language processes and overt motor behavior in the first $200 \mathrm{msec}$ of processing. Journal of Cognitive Neuroscience, 18(10), 1607-15.

Connell, L., \& Lynott, D. (2012). When does perception facilitate or interfere with conceptual processing? The effect of attentional modulation. Frontiers in Psychology, 3, 474. https://doi.org/10.3389/fpsyg.2012.00474

Connell, L., Lynott, D., \& Dreyer, F. (2012). A functional role for modality-specific perceptual systems in conceptual representations. PloS One, 7(3), e33321. https://doi.org/10.1371/journal.pone.0033321

Facchini, S., Romani, M., Tinazzi, M., \& Aglioti, S. M. (2002). Time-related changes of excitability of the human motor system contingent upon immobilisation of the ring and little fingers. 
Clinical Neurophysiology, 113(3), 367-375. https://doi.org/10.1016/S1388-2457(02)000093

Fargier, R., Paulignan, Y., Boulenger, V., Monaghan, P., Reboul, A., \& Nazir, T. A. (2012). Learning to associate novel words with motor actions: language-induced motor activity following short training. Cortex; a Journal Devoted to the Study of the Nervous System and Behavior, 48(7), 888-899. https://doi.org/10.1016/j.cortex.2011.07.003

Ferrand, L., Brysbaert, M., Keuleers, E., New, B., Bonin, P., Méot, A., ... Pallier, C. (2011). Comparing word processing times in naming, lexical decision, and progressive demasking: evidence from chronolex. Frontiers in Psychology, 2, 306. https://doi.org/10.3389/fpsyg.2011.00306

Fischer, M. H., \& Zwaan, R. A. (2008). Embodied language: a review of the role of the motor system in language comprehension. Quarterly Journal of Experimental Psychology (Colchester), 61(6), 825-50.

Gallese, V. (2005). Embodied simulation: from neurons to phenomenal experience. Phenomenology and Cognitive Sciences, 4, 29-48.

Glenberg, A. M., \& Kaschak, M. P. (2002). Grounding language in action. Psychonomic Bulletin Review, 9(3), 558-65.

Hauk, O., Johnsrude, I., \& Pulvermuller, F. (2004). Somatotopic representation of action words in human motor and premotor cortex. Neuron, 41(2), 301-7.

Heim, C. M., Mayberg, H. S., Mletzko, T., Nemeroff, C. B., \& Pruessner, J. C. (2013). Decreased cortical representation of genital somatosensory field after childhood sexual abuse. The American Journal of Psychiatry, 170(6), 616-623. https://doi.org/10.1176/appi.ajp.2013.12070950

Hostetter, A. B., \& Alibali, M. W. (2008). Visible embodiment: gestures as simulated action. Psychonomic Bulletin \& Review, 15(3), 495-514.

Huber, R., Ghilardi, M. F., Massimini, M., Ferrarelli, F., Riedner, B. A., Peterson, M. J., \& Tononi, G. (2006). Arm immobilization causes cortical plastic changes and locally decreases sleep slow wave activity. Nature Neuroscience, 9(9), 1169-76. https://doi.org/10.1038/nn1758

Humphries, S., Holler, J., Crawford, T. J., Herrera, E., \& Poliakoff, E. (2016). A third-person perspective on co-speech action gestures in Parkinson's disease. Cortex; a Journal Devoted to the Study of the Nervous System and Behavior, 78, 44-54. https://doi.org/10.1016/j.cortex.2016.02.009

James, K. H., \& Maouene, J. (2009). Auditory verb perception recruits motor systems in the developing brain: an fMRI investigation. Developmental Science, 12(6), F26-34. https://doi.org/10.1111/j.1467-7687.2009.00919.x

Jirak, D., Menz, M. M., Buccino, G., Borghi, A. M., \& Binkofski, F. (2010). Grasping language--a short story on embodiment. Consciousness and Cognition, 19(3), 711-20. https://doi.org/10.1016/j.concog.2010.06.020

Kemmerer, D., \& Gonzalez-Castillo, J. (2008). The Two-Level Theory of verb meaning: An approach to integrating the semantics of action with the mirror neuron system. Brain and Language, 112(1), 54-76.

Kiefer, M., Sim, E. J., Liebich, S., Hauk, O., \& Tanaka, J. (2007). Experience-dependent plasticity of conceptual representations in human sensory-motor areas. J Cogn Neurosci, 19(3), 52542. https://doi.org/10.1162/jocn.2007.19.3.525Kuznetsova, A., Bruun Brockhoff, P., \& Haubo Bojesen Christensen, R. (2014). lmerTest: Tests for random and fixed effects for linear mixed effect models (lmer objects of lme4 package). $\mathrm{R}$ package version 2.0-6. Available from: http://CRAN.R-project.org/package=lmerTest.

Liepelt, R., Dolk, T., \& Prinz, W. (2012). Bidirectional semantic interference between action and speech. Psychological Research, 76(4), 446-55. https://doi.org/10.1007/s00426-011-0390-z

Meugnot, A., Agbangla, N. F., \& Toussaint, L. (2016). Selective impairment of sensorimotor representations following short-term upper-limb immobilization. Quarterly Journal of $\begin{array}{llll}\text { Experimental Psychology } & \text { (2006), } & \text { 69(9), }\end{array}$ 
https://doi.org/10.1080/17470218.2015.1125376

Meugnot, A., Almecija, Y., \& Toussaint, L. (2014). The embodied nature of motor imagery processes highlighted by short-term limb immobilization. Exp Psychol, 61(3), 180-6. https://doi.org/10.1027/1618-3169/a000237

Meugnot, A., \& Toussaint, L. (2015). Functional plasticity of sensorimotor representations following short-term immobilization of the dominant versus non-dominant hands. Acta Psychol (Amst), 155, 51-6. https://doi.org/10.1016/j.actpsy.2014.11.013

Moisello, C., Bove, M., Huber, R., Abbruzzese, G., Battaglia, F., Tononi, G., \& Ghilardi, M. F. (2008). Short-term limb immobilization affects motor performance. Journal of Motor Behavior, 40(2), 165-76. https://doi.org/10.3200/JMBR.40.2.165-176

Pulvermüller, F. (2005). Brain mechanisms linking language and action. Nature Review Neuroscience, 6(7), 576-82.

Pulvermüller, F. (2013). How neurons make meaning: brain mechanisms for embodied and abstractsymbolic semantics. Trends in Cognitive Sciences, 17(9), 458-70. https://doi.org/10.1016/j.tics.2013.06.004

Pulvermüller, F., \& Fadiga, L. (2010). Active perception: sensorimotor circuits as a cortical basis for language. Nat Rev Neurosci, 11(5), 351-60.

R Core Team (2014). R : A language and environment for statistical computing. $R$ Foundation for Statistical Computing. Vienna, Austria: Author. http://www.R-project.org/

Spieler, D. H., \& Balota, D. A. (1997). Bringing Computational Models of Word Naming down to the Item Level. Psychological Science, 8(6), 411-416.

Springer, A., Huttenlocher, A., \& Prinz, W. (2012). Language-induced modulation during the prediction of others' actions. Psychological Research. https://doi.org/10.1007/s00426-0120411-6

Springer, A., \& Prinz, W. (2010). Action semantics modulate action prediction. Quarterly Journal of Experimental Psychology (Colchester), 1-18.

Taniguchi, Y. (1999). Effect of practice in bilateral and unilateral reaction-time tasks. Perceptual and Motor Skills, 88(1), 99-109. https://doi.org/10.2466/pms.1999.88.1.99

Tettamanti, M., Buccino, G., Saccuman, M. C., Gallese, V., Danna, M., Scifo, P., ... Perani, D. (2005). Listening to action-related sentences activates fronto-parietal motor circuits. Journal of Cognitive Neuroscience, 17(2), 273-81.

Toussaint, L., \& Meugnot, A. (2013). Short-term limb immobilization affects cognitive motor processes. Journal of Experimental Psychology: Learning Memory \& Cognition, 39(2), 623-32. https://doi.org/10.1037/a0028942

Willems, R. M., \& Hagoort, P. (2007). Neural evidence for the interplay between language, gesture, and action: a review. Brain Langage, 101(3), 278-89.

Willems, R. M., Toni, I., Hagoort, P., \& Casasanto, D. (2010). Neural dissociations between action verb understanding and motor imagery. Journal of Cognitive Neuroscience, 22(10), 2387400. https://doi.org/10.1162/jocn.2009.21386

Zwaan, R. A., \& Taylor, L. J. (2006). Seeing, acting, understanding: motor resonance in language comprehension. Journal of Experimental Psychology: General, 135(1), 1-11. 


\section{APPENDIX}

Table A.1: Means (Standard Deviations) for accuracy (in \%) and response times (in ms) as a function of hand-action and foot-action verbs for both groups (control and immobilized).

Hand-action verbs

Foot-action verbs

\begin{tabular}{lcccc} 
Group & Accuracy (\%) & Response times (ms) & Accuracy (\%) & Response times (ms) \\
\hline Control & $97.4(2.3)$ & $912(83)$ & $97.6(2.3)$ & $957(104)$ \\
\hline Immobilized & $98.8(1.2)$ & $934(143)$ & $97.8(2.8)$ & $941(152)$ \\
\hline
\end{tabular}

Table $\mathrm{A}_{.2}$ : Means (Standard Deviations) for accuracy (in \%) and response times (in ms) as a function of hand-action and foot-action verbs and tests (pre-test and post-test) for both groups (control and immobilized).

Hand-action verbs

Foot-action verbs

Group Accuracy (\%) Response times (ms) Accuracy (\%) Response times (ms)

\begin{tabular}{ccccc}
\hline $\begin{array}{c}\text { Control } \\
\text { Pre-test }\end{array}$ & $99.1(1.0)$ & $918(79)$ & $98.1(1.5)$ & $945(89)$ \\
Post-test & $99.3(1.0)$ & $832(77)$ & $99.0(1.4)$ & $851(81)$ \\
\hline Immobilized & & & & \\
Pre-test & $98.7(1.6)$ & $911(101)$ & $98.6(1.6)$ & $944(126)$ \\
Post-test & $99.1(1.1)$ & $858(115)$ & $98.8(1.3)$ & $857(125)$ \\
\hline
\end{tabular}


Table A.3: List of the hands-action verbs used in the semantic decision task. English translation of each verb appears in brackets.

\section{Hands-action verbs}

\begin{tabular}{llll}
\hline Action Verbs & Frequency & Number of letters & Number of syllabes \\
\hline Ecrire (write) & 305.92 & 6 & 2 \\
Jeter (throw) & 192.18 & 5 & 2 \\
Lâcher (release) & 171.08 & 6 & 2 \\
Couper (cut) & 155.82 & 6 & 2 \\
Effacer (clean) & 29.02 & 7 & 3 \\
Applaudir (clap) & 17.97 & 9 & 3 \\
Découper (slice) & 12.71 & 8 & 3 \\
Gratter (scrub) & 12.11 & 7 & 2 \\
Tracer (trace) & 10.49 & 6 & 2 \\
Coudre (sew) & 8.88 & 6 & 1 \\
Clouer (nail) & 7.52 & 6 & 2 \\
Gifler (slap) & 6.77 & 6 & 2 \\
Souligner (outline) & 4.72 & 9 & 3 \\
Tricoter (knit) & 3.19 & 8 & 3 \\
Palper (palpate) & 1.81 & 6 & 2 \\
Colorier (color) & 1.1 & 8 & 3 \\
Embrocher (skewer) & 0.71 & 9 & 3 \\
Tartiner (butter) & 0.65 & 8 & 3 \\
Dégrafer (unclip) & 0.59 & 6 & 3 \\
Gommer (erase) & 0.57 & 6 & 2 \\
Pagayer (paddle) & 0.42 & 6 & 3 \\
Natter (plait) & 0.11 & 6 & 2 \\
\hline
\end{tabular}


Table A.4: List of the feet-action verbs used in the semantic decision task. English translation of each verb appears in brackets.

\section{Feet-action verbs}

\begin{tabular}{|c|c|c|c|}
\hline Action Verbs & Frequency & Number of letters & Number of syllabes \\
\hline Marcher (walk) & 364.37 & 7 & 2 \\
\hline Courir (run) & 146.5 & 6 & 2 \\
\hline Danser (danse) & 137.36 & 6 & 2 \\
\hline Sauter (jump) & 123.03 & 6 & 2 \\
\hline Avancer (go forward) & 95.62 & 7 & 3 \\
\hline Reculer (go back) & 52.15 & 7 & 3 \\
\hline Shooter (shoot) & 6.84 & 7 & 2 \\
\hline Bondir (leap) & 5.1 & 6 & 2 \\
\hline Décamper (run away) & 4.02 & 8 & 3 \\
\hline Déraper (skid) & 3.85 & 7 & 3 \\
\hline Fouler (tread) & 3.06 & 6 & 2 \\
\hline Accroupir (squat) & 2 & 9 & 3 \\
\hline Valser (waltz) & 1.93 & 6 & 2 \\
\hline Pédaler (pedal) & 1.58 & 7 & 3 \\
\hline Dévaler (hurtle down) & 1.51 & 7 & 3 \\
\hline Sautiller (bounce) & 1.48 & 9 & 3 \\
\hline Tituber (stumble) & 1.34 & 7 & 3 \\
\hline Chausser (put on shoes) & 1.27 & 8 & 2 \\
\hline Enjamber (step over) & 0.86 & 8 & 3 \\
\hline Déchausser (take shoes o & 0.73 & 10 & 3 \\
\hline Trottiner (scamper aroun & 0.22 & 9 & 3 \\
\hline Slalomer (slalom) & 0.07 & 8 & 3 \\
\hline
\end{tabular}

